\title{
Staged perfusion with an axillary artery graft and deep hypothermia during descending aortic replacement
}

\author{
Toshiki Takahashi, MD, Yasuhisa Shimazaki, MD, Takao Watanabe, MD, Takashi Minowa, MD, \\ Masataka Koshika, MD, Kiyoshige Inui, MD, Jun Hosaka, MD, and Shuji Toyama, MD, Yamagata, Japan
}

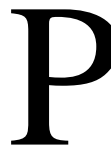

revention of neurologic injury is one of the most important goals in reconstruction of the distal aortic arch. Femoral perfusion has a potential of embolic ischemic events including stroke and visceral malperfusion ${ }^{1,2}$ in patients with chronic type B dissection. We have introduced an antegrade systemic perfusion technique via the left axillary artery graft for replacement of the

\footnotetext{
From the Second Department of Surgery, Yamagata University School of Medicine, Yamagata, Japan.

Received for publication Aug 16, 2000; accepted for publication Nov 30, 2000.

Address for reprints: Toshiki Takahashi, MD, Second Department of Surgery, Yamagata University School of Medicine, 2-2-2 Iidanishi, Yamagata, 990-

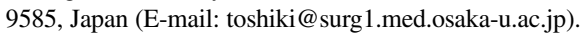

J Thorac Cardiovasc Surg 2001;122:188-9

Copyright $\odot 2001$ by The American Association for Thoracic Surgery

$0022-5223 / 2001 \$ 35.00+0 \quad \mathbf{1 2 / 5 4 / 1 1 3 3 2 7}$

doi:10.1067/mtc.2001.113327
}

descending thoracic aorta in 2 recent patients with chronic type B aortic dissection. This technique allows us to reconstruct the distal descending aorta, including the lower intercostal arteries, first during upper body cooling. We then can create an open proximal anastomosis with deep hypothermic retrograde cerebral perfusion with subsequent antegrade perfusion to the lower part of the body through the side branch of the distal aortic graft.

\section{Operative Technique}

The patient was intubated with a double-lumen tube and then placed in a left thoracotomy position, the hips swiveled for the femoral cannulation and the left upper arm hung for the axillary cannulation. After systemic heparinization, an 8-mm woven Dacron graft (Meadox Medicals, Inc, Oakland, NJ) was anastomosed to the left axillary artery and connected to an arterial cannula for an arterial line. Cardiopulmonary bypass was established with two venous cannulas via the right femoral vein and pulmonary artery trunk, and core cooling was commenced. A venting tube was also inserted into the left atrium. When the rectal temperature reached $25^{\circ} \mathrm{C}$, the distal descending thoracic aorta was clamped and opened circumferential- 

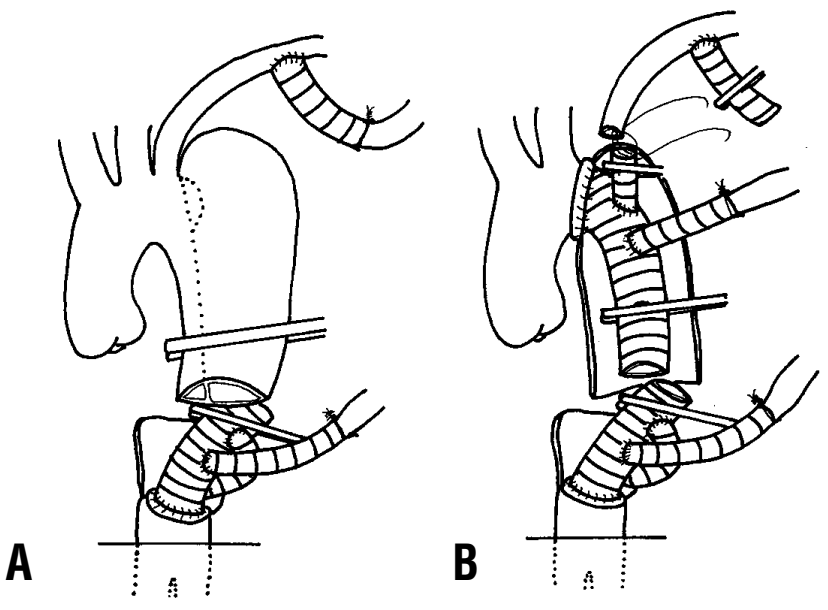

Figure 1. A, The open distal anastomosis was completed with reconstruction of lower intercostal arteries during cooling of the upper part of the body with left axillary artery graft perfusion, and antegrade perfusion to the lower part of the body was commenced through a side branch of the distal aortic graft. B, The left subclavian artery was reconstructed during rewarming through side branches of the proximal and distal aortic grafts to the upper and lower parts of the body, respectively.

ly above the diaphragm. The septum between the true and false lumina was widely excised and an open distal anastomosis was created with an aortic woven Dacron graft (Meadox Medicals), to which an 8-mm woven Dacron graft was attached in advance. Then, antegrade perfusion to the lower part of the body was immediately established through this side branch, and some lower intercostal arteries were reconstructed with a graft anastomosed end to side to the aortic graft (Figure $1, A$ ). The tympanic temperature reached $13^{\circ} \mathrm{C}$ to $18^{\circ} \mathrm{C}$ during these procedures and axillary perfusion was ceased. The patient was placed in a mild Trendelenburg position, and the central venous pressure was raised to $15 \mathrm{~mm} \mathrm{Hg}$ for retrograde cerebral perfusion. ${ }^{2}$ The distal arch was transected and another aortic woven Dacron graft was anastomosed to its proximal stump by means of the open proximal technique. Then, axillary perfusion to the upper part of the body was resumed and rewarming was started through both arterial inflows.

The first patient required reconstruction of the left subclavian artery because aortic dissection involved its orifice. In this patient, two 8-mm woven Dacron grafts were also attached to the proximal aortic graft in advance. Perfusion to the upper part of the body was re-established through one of the side branches and then the trimmed left subclavian artery was anastomosed end to end to another side branch (Figure 1, B). During rewarming, the proximal aortic graft was anastomosed to the distal one. Weaning from cardiopulmonary bypass was easy and the postoperative course was uneventful in both patients.

\section{Discussion}

The wall of the distal aortic arch is friable, and aneurysmal formation sometimes involves the left subclavian artery in patients with chronic type $\mathrm{B}$ dissection. Therefore, deep hypothermic circulatory arrest ${ }^{1}$ or its modification ${ }^{2}$ has been advocated for distal aortic arch reconstruction. However, neurologic injury including stroke is still one of the major causes of operative mortality and morbidity. ${ }^{1,2}$ Ergin and associates $^{1}$ reported that permanent neurologic deficit was a result of thromboembolic events, which were highly related to the presence of clot or atheroma in the aorta. Femoral perfusion may have a risk of embolic ischemic events and visceral malperfusion, especially in patients with a dissecting aortic aneurysm containing clot or atheroma. Therefore, we used systemic perfusion via the left axillary artery graft and subsequent antegrade perfusion to the lower part of the body from the side branch of the distal aortic graft. This technique constantly provides antegrade flow in the descending aorta that, we believe, minimizes the risk of embolism in the spinal cord and viscera. Concomitant reconstruction of lower intercostal arteries with an interposed graft will provide prompt restoration of spinal cord blood flow and easier hemostasis at each anastomotic site than conventional end-to-side direct anastomosis. ${ }^{3}$

Direct cannulation into the axillary artery has a risk of vascular injury and postoperative stenosis of the cannulated site. Baribeau and coworkers ${ }^{4}$ advocated an arterial inflow via the right axillary artery graft for cardiovascular surgery through a median sternotomy in patients having a severely atheromatous ascending aorta. We have introduced this graft interposition technique on the left side for distal aortic arch surgery through a left thoracotomy, which also avoids vascular complications and provides easy handling of the arterial line in the operative field. On the other hand, perfusion via the left axillary artery causes retrograde flow in the arch, from which debris or thrombus can be released and cause brain embolism during the cooling period. However, retrograde cerebral perfusion during deep hypothermia has a potential of flushing out the emboli in the arch branches. 2,5 Therefore, the staged perfusion reported here may minimize the risk of brain embolism. Practically, it is easier in the left thoracotomy position to approach the left axillary artery than the right one. If both axillary arteries were also diseased, the left ventricular cannula might be an alternative as an arterial line ${ }^{6}$ in such a special case.

In conclusion, our antegrade systemic perfusion technique initiated with the left axillary artery will reduce the risk of embolic ischemic events and visceral malperfusion and will provide superior protection against cerebral and spinal cord ischemia.

\section{References}

1. Ergin MA, Galla JD, Lansman SL, Quintana C, Bodian C, Griepp RB. Hypothermic circulatory arrest in operations on the thoracic aorta. Determinants of operative mortality and neurologic outcome. J Thorac Cardiovasc Surg. 1994;107:788-99.

2. Takamoto S, Okita Y, Ando M, Morota T, Handa N, Kawashima Y. Retrograde cerebral circulation for distal aortic arch surgery through a left thoracotomy. J Card Surg. 1994;9:576-83.

3. Elefteriades JA, Coady MA, Nikas DJ, Kopf GS, Gusberg RJ. "Cobrahead" graft for intercostal artery implantation during descending aortic replacement. Ann Thorac Surg. 1995;60:67-77.

4. Baribeau YR, Westbrook BM, Charlesworth DC, Maloney CT. Arterial inflow via an axillary artery graft for the severely atheromatous aorta. Ann Thorac Surg. 1998;66:33-7.

5. Watanabe T, Shimazaki T, Kuraoka S, Abe H, Iijima Y, Washio M. Retrograde cerebral perfusion against massive air embolism during cardiopulmonary bypass. J Thorac Cardiovasc Surg. 1992;104:532-3.

6. Golding LAR. New cannulation technique for the severely calcified ascending aorta. J Thorac Cardiovasc Surg. 1985;90:626-7. 